\title{
Seed germination studies of tree species: Radermarchera xylocarpa and Dolicandrone falcata
}

\author{
D. R. Trivedi, A. G. Joshi* and P. S. Nagar
}

Department of Botany, Faculty of Science, The M.S.University of Baroda, Sayajigunj, Vadodara-390021, India

\begin{abstract}
Seeds of Radermarchera xylocarpa and Dolicandrone falcata were soaked overnight in water and germinated in different substrates. In both the plants, the highest percent of germination was recorded in cocopeat (Radermarchera xylocarpa:62\%; Dolicandrone. falcata: 41\%) followed by MS basal medium (Radermarchera xylocarpa: 46\%; Dolicandrone falcata:20\%), cocopeat: sand (Radermarchera xylocarpa:30\%; Dolicandrone. falcata: 8\%) and least being in filter paper (Radermarchera xylocarpa: 23\%; Dolicandrone falcata: 0\%).

Prior to germination in optimised substrate, seeds were soaked overnight in distilled water (control) and in gibberllic acid (GA 3$)(5 \& 10$ $\mu \mathrm{M})$. In both the plants $\mathrm{GA}_{3}$ treated seeds failed to increase percent germination and the growth of seedlings. In control the seedling growth was better with respect to all the parameter for both the species. Seedlings which were grown in cocopeat, rapidly developed into healthy plants after transfer to field
\end{abstract}

Keywords: Cocopeat; D. falcata; Germination; Growth; R. xylocarpa; Seedling

\section{Introduction}

The Indian Flora is rich in medicinal plants and over 7000 different plant species present in the different ecosystems are used for various medicinal purposes (Rajendra and Souza, 1999). To meet the growing demand of herbal/medicinal industries, these plant resources especially the tree species are exploited in the country and are rapidly being extinct from the wild.

Under natural conditions, the seeds of some tree species have low percent of germination and are difficult to grow through conventional methods. Because of that their large scale plantations becomes limited. Such seeds must be pretreated to hasten germination and seedling establishment (Maku et al., 2014). Recent advances in agricultural research has suggested that the improvement in crop productivity and quality can be further enhanced by incorporating new technologies in the traditional breeding programs (Mhatre and Rao, 1998). In tree species there are several reports which mention methods for enhancing the seed germination as well as growth of seedlings (Azad et al., 2011; Kandya, 1990; Khan et al., 2001; Annapurna et al., 2005; Maku et al., 2014; Trivedi and Joshi, 2012 and 2014).

Radermarchera xylocarpa and Dolicandrone falcata are tree species belonging to family Bignoniaceae, which are an important component of semi-moist forests. But due to poor natural regeneration, harvesting them from the wild has placed these plants under threat category.

Radermarchera xylocarpa (Roxb.) Schum is a critically endangered middle sized deciduous tree belonging to family Bignoniaceae, growing up to 5-10 m tall. Capsules are 1-3 ft. long slightly curved, rough with numerous winged seeds. The oil from the wood is used in cutaneous affections and resin extracted from it, is used in skin diseases as well as an antiseptic (Kirtikar and Basu, 1975).

Dolichandrone falcata (Wall. ex DC) Seem is a small deciduous tree belonging to family Bignoniaceae, growing up to 20-50 ft. tall which is now placed under vulnerable category. Capsules are flat much falcately curved, glaborous bearing seeds which are broad, rectangular and winged. Traditionally the juice of leaves is used for treatment of diabetes and decoction of the fruit is used medicinally (Kirtikar and Basu, 1975).

The propagation for both the plants is mainly through seeds (Cooke, 1908).These trees are important component of semimoist forest, but are poor in natural regeneration (Sabnis and Amin, 1992). Hence propagation of these members is essen-

*Corresponding author. e-mail: drarunajoshi@yahoo.co.in 
tial and therefore the present work on seed germination studies of R. xylocarpa and D. falcata was taken up with an aim to improve the rate of germination utilizing different substrates. It was carried out with two objectives. Initially the planting substrate was standardised for developing large number of seedlings, and then different growth parameters were studied in the optimised substrate.

\section{Materials and methods}

Seeds of $R$. xylocarpa (Plate 1.a) were collected from Shoolpaneshwar and D. falcata (Plate 1.e) were collected from Dharampur forest. To carry out seed germination studies of these species, the substrates utilized were, cocopeat, cocopeat:sand(1:1), sand, filter paper and MS Basal medium.

150 gms of cocopeat (dry weight) was soaked in distilled water (4 times of dry weight) overnight. Except sand, individual cocopeat, a mixture of cocopeat and sand (1:1), petriplates with filter paper and MS basal medium were autoclaved at $15 \mathrm{psi}$ for $25 \mathrm{~min}$.

Seed germination in three different planting substrates under aseptic conditions

Seeds were soaked overnight in distilled water (control), treated with $0.1 \% \mathrm{HgCl}_{2}$ for 2 minutes and were washed 3 times with sterile water. All the manipulations for germinating the seeds were carried out in the Laminar air flow cabinet for the following substrates:

\section{Cocopeat and Cocopeat:Sand}

The seeds were germinated singly in each well of the root trainer containing a specific type of substrate. Bavistin $(200 \mathrm{mg} / \mathrm{l})$ was added on to the substrate and the root trainers were kept in culture room at $25 \pm 2{ }^{\circ} \mathrm{C}$.

\section{MS Basal Medium}

5 seeds were kept per flask containing basal medium and these were kept in culture room at $25 \pm 2^{\circ} \mathrm{C}$.

\section{Filter paper}

5-10 $\mathrm{ml}$ sterile water was added in each petridish with filter paper. Thereafter 5 seeds were inoculated in ten petridishes and were sealed with parafilm. All the petridish were kept in culture room at $25 \pm 2{ }^{\circ} \mathrm{C}$.

In vivo seed germination in sand

Sand $(2.2 \mathrm{Kg})$ was filled in polybags and single seeds (overnight soaked in distilled water) were planted in each bag. Fifty polybags were used for the experimental studies and daily watered to keep the substrate moist.

\section{Seed germination and growth in cocopeat}

Seeds were soaked in $\mathrm{GA}_{3}(5 \mu \mathrm{M}$ and $10 \mu \mathrm{M})$ solution overnight and were germinated in cocopeat substrate filled in root trainers. These root trainers were kept in culture room at $25 \pm 2{ }^{\circ} \mathrm{C}$. After seedling emergence, 5 seedlings from each treatment as well as control (seeds soaked in distilled water) were randomly selected and observations for percent germination and growth parameters like seedling length (shoot and root length), fresh weight, dry weight and collar diameter were recorded after 20 days in $R$. xylocarpa and in D. falcata.

\section{Results and discussion}

Results showed that out of the different planting substrates that were used to study the seed germination by soaking the seeds in distilled water, cocopeat proved to be a better substrate compared to all others in both the species $R$. xylocarpa and $D$. falcata (Fig.1). It resulted into highest percent of germination (62\%) (Fig.1) in R. xylocarpa (Plate 1.b) while it was $41.4 \%$ in D. falcata (Fig.1, Plate 1.f) followed by MS medium with $46 \%$ and $20 \%$, which was higher as compared to cocopeat: sand. While in the other two substrates ie. sand and filter paper, lowest percent of germination was recorded.Earlier studies on seed germination in different planting substrates in Bignoniaceae members, O. indicum (Trivedi and Joshi, 2012) and S. suaveolens (Trivedi and Joshi, 2014), also reports cocopeat to be optimum for highest percentage of seed germination.

Seed germination is regarded as a series of steps which occur prior to the emergence of radical from the seed coat (Mayerand and Shain, 1974, Rahman et al., 2007).Since cocopeat and MS medium proved to be beneficial for seed germination, these substrates were evaluated weekly for seedling emergence in both the species and it was noted that, from first week to the third week, number of seedlings 


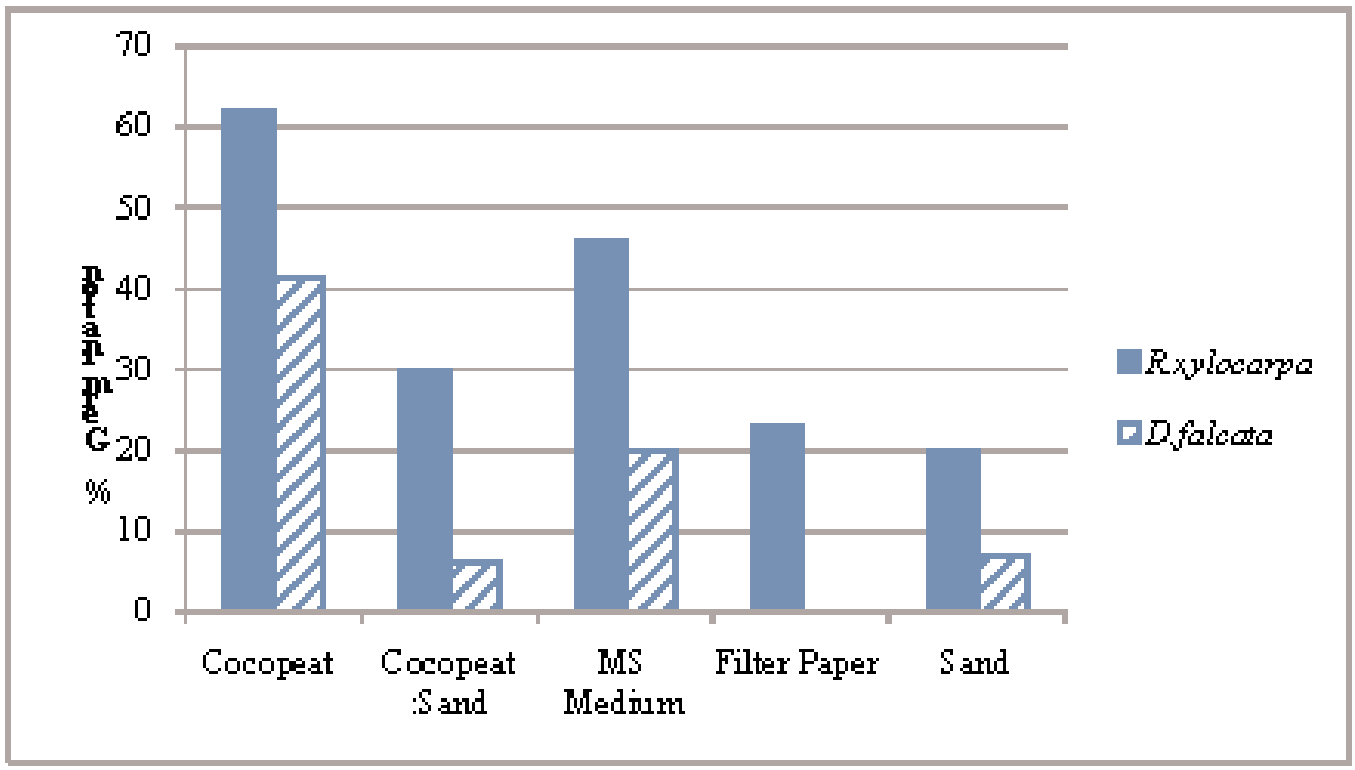

Fig.1. Seed germination in different substrates in $R$. xylocarpa and D. falcata

increased every week in both the substrates (Fig. 2). In $R$. xylocarpa it increased from 20 to $44 \%$ whereas in $D$. falcata it was from 7 to $29 \%$ in cocopeat substrate. In MS medium the percentage increased from 15 to $23 \%$ in Radermarchera and 3 to $10 \%$ in Dolicandrone. It was found that the growth of the seedlings in MS medium was normal but when transferred to in vivo conditions, they failed to survive. Cocopeat proved to be better substrate than MS Basal medium in terms of growth for both the plants.
The effect of gibberllic acid $\left(\mathrm{GA}_{3}\right)$ on germination and growth of seedlings in both the species showed that $\mathrm{GA}_{3}$ failed to improve percent germination as it was less than the control (Fig. 3). Usually gibberellic acid is used to promote seed germination (Joshi et al. 2010; Yamaguchi and Kamiva, 2001), but in the present studies it proved to be inhibitory. Similar results are reported in $P$. brevifolia (Wall et al., 2010). Seeds soaked in distilled water proved to be better than the $\mathrm{GA}_{3}$ treated seeds and similar findings are observed in Tetrapleura tetraptera (Maku et al., 2014).

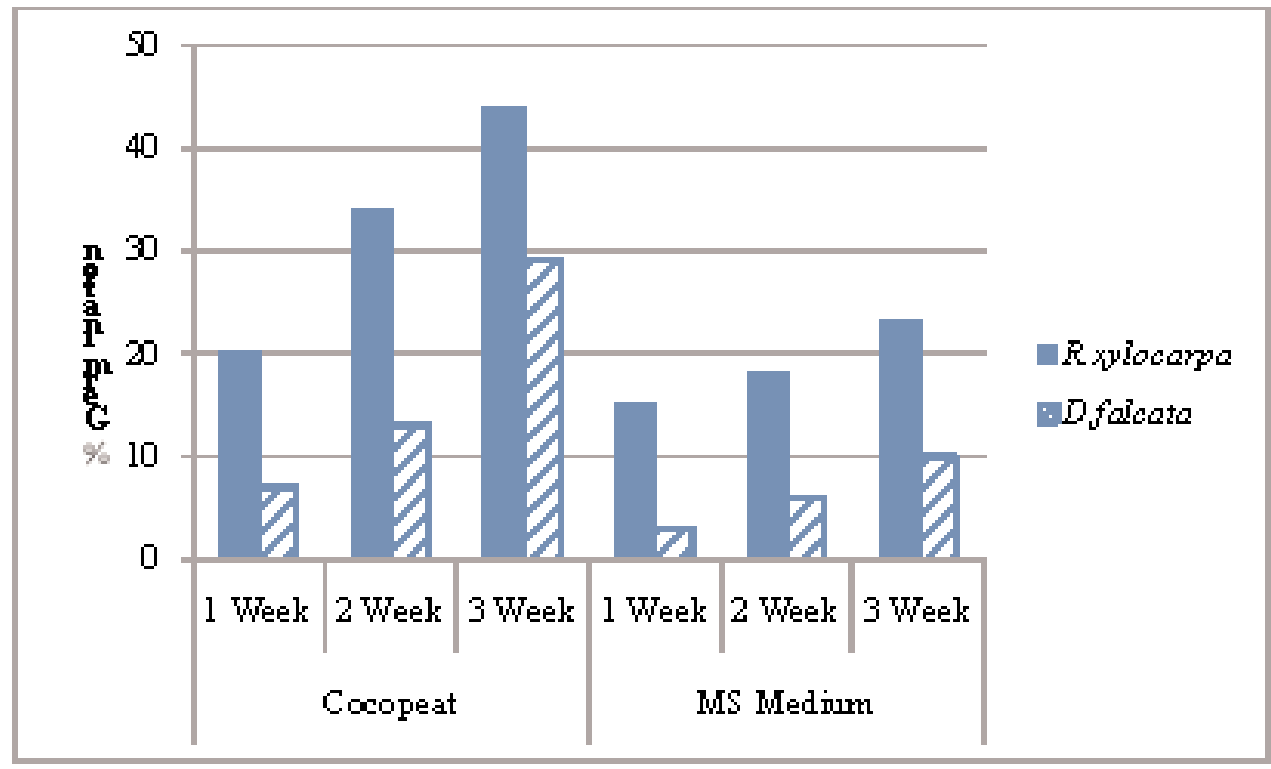

Fig. 2. Weekly percent germination in cocopeat and MS medium of $R$. xylocarpa and $D$. falcata 


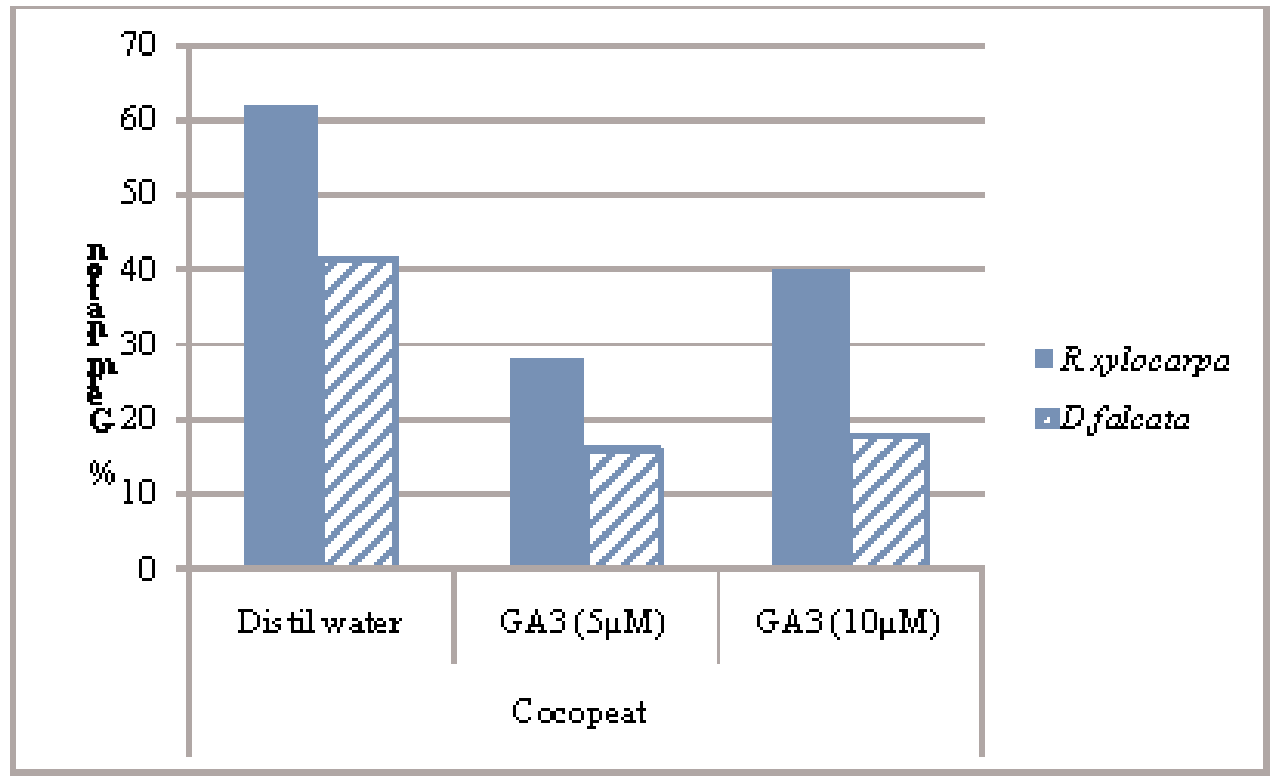

Fig. 3. Effects of Gibberllic acid on seed germination in cocopeat of $R$. xylocarpa and $D$. falcata

The assessment of growth parameters for seedlings of Radermarchera (Plate 1.c) in control showed that the length $(3.3 \mathrm{~cm}$ ), biomass (FW: 0.14g; DW: 0.01g) was better than $\mathrm{GA}_{3}(5 \& 10 \mu \mathrm{M})$ except for collar diameter $(0.7 \mathrm{~cm})$ which was higher in $5 \mu \mathrm{M}$ of $\mathrm{GA}_{3}$ (Table I). overall growth of seedlings in the two species. Similar obser vations were recorded in Tetrapleura tetraptera in which least performance in seedling growth characteristics was observed in $\mathrm{GA}_{3}$ treated seedlings compared to control (Maku et al., 2014).

Table I. Growth parameters in $R$. xylocarpa and $D$. falcata seedlings in cocopeat substrate

\begin{tabular}{llcccc}
\hline Plant Species & \multicolumn{1}{c}{ Seed soaked } & Length $(\mathrm{cm})$ & Collar diameter $(\mathrm{cm})$ & FW $(\mathrm{g})$ & DW $(\mathrm{g})$ \\
\hline \multirow{3}{*}{ R. xylocarpa } & Distilled water & $3.3 \pm 0.11$ & $0.66 \pm 0.02$ & $0.14 \pm 0.015$ & $0.010 \pm 0.001$ \\
& Gibberllic Acid $(5 \mu \mathrm{M})$ & $2.6 \pm 0.27$ & $0.7 \pm 0.05$ & $0.08 \pm 0.009$ & $0.010 \pm 0.001$ \\
& Gibberllic Acid $(10 \mu \mathrm{M})$ & $2.8 \pm 0.13$ & $0.44 \pm 0.05$ & $0.08 \pm 0.010$ & $0.008 \pm 0.002$ \\
& Distilled water & $4.7 \pm 0.7$ & $0.68 \pm 0.06$ & $0.33 \pm 0.017$ & $0.040 \pm 0.003$ \\
D. falcata & Gibberllic Acid $(5 \mu \mathrm{M})$ & $2.3 \pm 0.5$ & $0.8 \pm 0.03$ & $0.17 \pm 0.036$ & $0.030 \pm 0.004$ \\
& Gibberllic Acid $(10 \mu \mathrm{M})$ & $1.8 \pm 0.3$ & $0.74 \pm 0.10$ & $0.15 \pm 0.015$ & $0.030 \pm 0.003$
\end{tabular}

In Dolicandrone falcata, seedlings (control) (Plate 1.g) recorded maximum length $(4.7 \mathrm{~cm})$ and biomass $(\mathrm{FW}: 0.33 \mathrm{~g}$; DW: $0.04 \mathrm{~g}$ ) compared to $\mathrm{GA}_{3}$ except collar diameter which was higher $(0.8 \mathrm{~cm})$ in seedlings of $\mathrm{GA}_{3}(5 \mu \mathrm{M})$ (Table I).

Hence from the above results it could be inferred that $\mathrm{GA}_{3}$ pretreatment was not effective for germination and growth in both the species. The distilled water soaking was helpful for
As cocopeat substrate generated highest number of seedlings in both species, these seedlings were transferred to pots containing soil and were kept in garden for their further growth. It was observed that the seedlings of both species developed into a very healthy plants within a month showing vigorous growth and attained a considerable height within three months (Plate 1. d, h) Improved growth of seedlings using cocopeat has been reported in number of other species like 

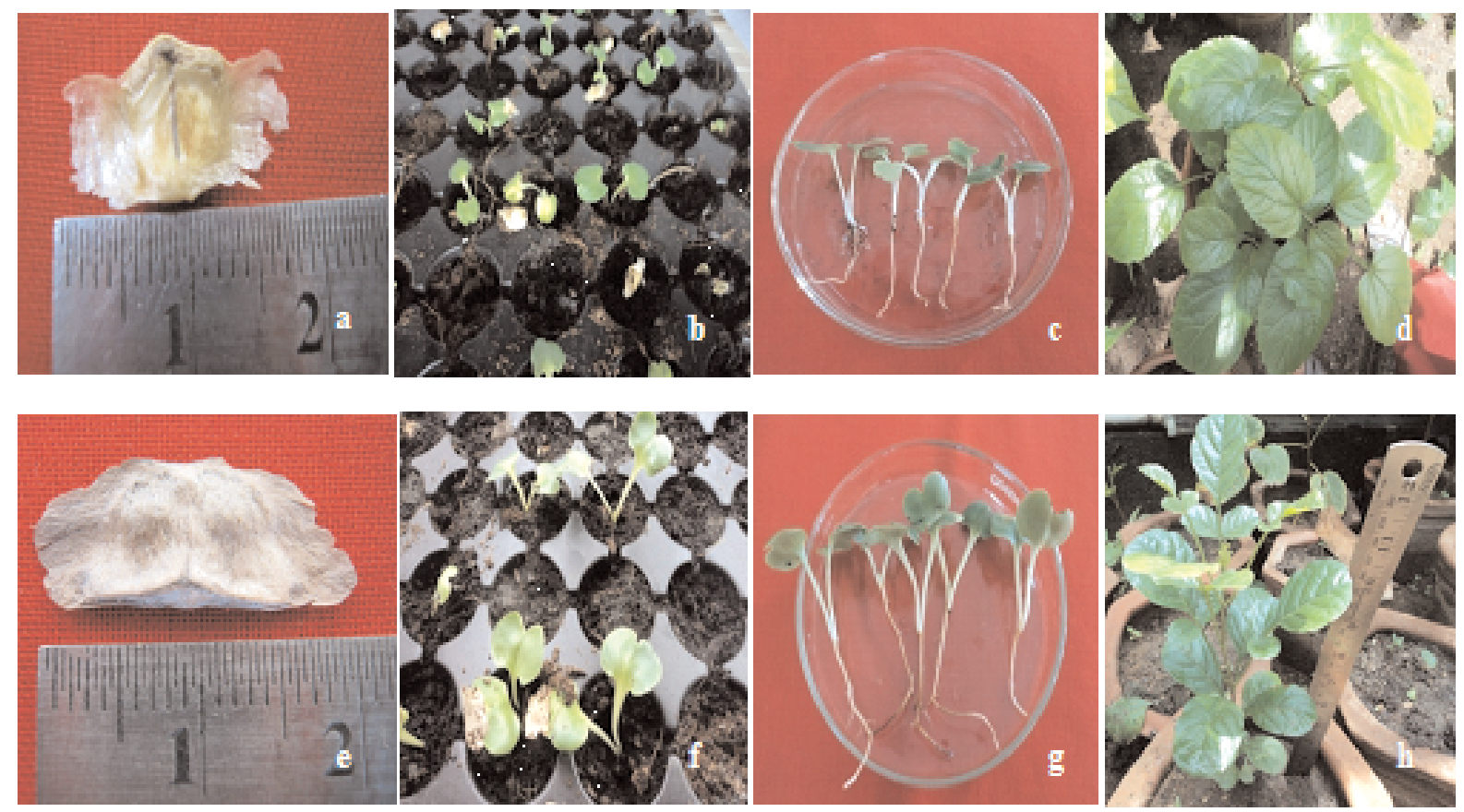

Plate 1: Radermarchera xylocarpa (a) Winged seed (b) Germination of seeds in cocopeat (c) Healthy seedlings after 20 days (d) Three month old plants growing in pots

Dolicandrone falcata (e) Winged Seed (f) Germination of seeds in cocopeat (g) Healthy seedlings after 20 days (h) Three month old plants growing in pots

Pterocarpus macrocarpus (Kijkar, 1991), Eucalyptus tereticornis (Kumar and Marimuthu, 1997) and Swietenia macrophylla (Woods et al., 1998).

Cocopeat was found to be a suitable substrate for germination and growth of $R$. xylocaropa and D. falcata seeds.

\section{References}

Annapurna D, Rathore TS and Joshi G (2005), Refinement of potting medium ingredients for production of high quality seedlings of sandalwood (Santalum album L.), Australian Forest 68: 44-49.

Azad MS, Manik MR, Hasan MS, Matin MA (2011), Effect of different pre sowing treatments on seed germination percentage and growth performance of Acacia auriculiformis, J. Forest Res. 22:183-188.

Cooke T (1908), Flora of the Presidency of BombayCompositae to Gramineae Vol.2, Taylor and Francis, London pp 329 -333.
Joshi SC, Preeti D, Parihar SS, Negi HCS (2010), Effect of $\mathrm{GA}_{3}$ on seed germination of Pyracantha crenulata (D.Don.) M. Roem. New York Sci. J. 3: 55-57.

Kandya S (1990), Enhancing germination in Cassia siamea seeds. J. Trop Forest. 6: 28-35.

Khan BM, Koirala B, Hossian MK (2001), Effect of different pre sowing treatments on germination and seedling growth attributes in Ghora Neem (Melia azedarach L.) Malaysian Forest 64: 14-21.

Kijkar S (1991), Handbook: Coconut husk as a potting medium. ASEAN-Canada Forest Tree Seed Centre Project, Muak -Lek, Saraburi, Thailand, pp 14.

Kirtikar KR and Basu BD (1975), Indian Medicinal Plants. $2^{\text {nd }}$ Ed. International book Distributors, Dehradun, India. 3 pp 1844, 1850.

Kumar A and Marimuthu T (1997), Decomposed coconut coir pith-a good nursery media mix for Eucalyptus spp. Indian forester, 122: 769-772. 
Maku JO, Gbadamosi AE and Oke SA (2014), Effect of some growth hormones on seed germination and seedling growth of Tetrapleura tetraptera (Thaub, Intern. J. Plant Res. 4: 36-42.

Mayerand AM and Shain Y (1974), Control of seed germination Ann. Rev. Plant Physiol. 25: 167-193.

Mhatre M and Rao PS (1998), Plant tissue culture - current trends and future prospects, In: Advances in plant physiology. (Ed.) Hemantranjan A Sci. Publ., Jodhpur, India pp 72-101.

Rahman MM, Banu LA, Rahman MM and Shahjadee UF (2007), Changes of the enzyme activity during germination of different mungbean varieties, Bangladesh $J$. Sci. Ind. Res. 42 (2): 213-216.

Rajendra K and Souza LD (1999), In vitro Propagation of Ayurvedic Plants, in Role of Biotech. in Medicinal and Aromatic plants, eds Khan I.A and Khanum A., Ukaaz, Hyderabad 2, pp 207-237.

Sabnis SP and Amin, JV (1992), Ecoenvironmental studies of Sardar Sarovar Environs SSNN Ltd. N.P.G Gandhinagar:20

Trivedi D and Joshi AG ( 2012), Effect of substrates on the growth of Oroxylum indicum (Vent.), Indian Forester 138: $1069-1070$.
Trivedi DR and Joshi AG (2014), Studies on seed germination of Stereospermum suaveolens with respect to different parameters, Environ. Expt. Biol. 12: 33-37.

Wall WA, Hilton JL, Wentworth TR, Gray JB, Hohmann MG and Hohmann WA (2010), Effects of light and temperature on germination of Pyxidanthera brevifolia Wells (Diapensiaceae), J. Torry Bot. Soc. 137: 348-354.

Woods PV, Peseta O and Webb MJ (1998), Effectiveness of organic potting media for raising mahogany (Swietenia macrophylla) seedlings in western Samoa, J. Tropical Forest Sci.10: 555-560.

Yamaguchi S and Kamiva Y (2001), Gibberllins and light stimulated seed germination, J. Plant Growth Regul. 20: $369-376$.

Received: 17 May 2015; Revised: 15 November 2015; Accepted: 31 January 2016. 